\title{
SOBRE LA FORTUNA DE ARISTÓTELES EN ESPAÑA
}

\author{
Ángel Escobar Chico \\ Universidad de Zaragoza
}

En tanto la aparición de un trabajo de conjunto y con ciertas pretensiones acerca de la pervivencia de Aristóteles en España sea sólo un desideratum más o menos urgente, nuestra información al respecto habrá de seguir recabándose entre la multitud de contribuciones parciales que, desde hace décadas, se han dedicado a asediar el problema. ${ }^{1}$ Con resultados desiguales en extensión y profundidad pero siempre dignos de consideración, los estudios realizados sobre nuestro Aristóteles (Graecus, Latinus, Arabus, Hebraeus y, por así llamarlo, Hispanicus) ${ }^{2}$ ya permiten esbozar una valoración de conjunto algo matizada y que, en mayor o menor medida, cabía prever desde que la vexata quaestio del humanismo español y sus méritos comenzó a plantearse con cierta objetividad, es decir, sin apasionamientos y desmesuras de uno $u$ otro signo tendentes a enmascarar o maquillar lo evidente. ${ }^{3}$

Como es sabido, la lucha entre la fervorosa asunción del aristotelismo y su rechazo no menos entusiasta determina buena parte de la historia cultural europea desde el siglo XII (desde algo antes y con un trasfondo ideológico bastante distinto en la parte oriental,

1 Nos hemos propuesto publicar próximamente un inventario crítico de las mismas, como primer paso para facilitar el estudio sistemático de la cuestión.

2 Bajo cuya denominación podría incluirse el estudio de las traducciones a lenguas hispánicas, paráfrasis, comentarios, citas, presencia literaria (como personaje y como fuente o autoridad doctrinal), etc.

3 Así, frente al entusiasmo no siempre fundado de D. Marcelino Menéndez Pelayo acerca de la «larga y gloriosa historia» de nuestros estudios griegos (cf. Biblioteca de traductores españoles, ed. E. Sánchez Reyes, Santander, 1953, III, p. 100), creemos que L. Gil ha conseguido matizar la virtud de dicha historia (cf., como síntesis de su ideario, Panorama social del humanismo español (1500-1800), Madrid, 1981; compartimos la valoración de sus aportaciones expresada por J. L. Moralejo, «Luis Gil y la historia del humanismo español», Anthropos, 104, 1990, pp. 56-59). Recientemente ha aparecido la bienvenida obra de A. Gómez Moreno, España y la Italia de los humanistas. Primeros ecos, Madrid, 1994 (con un capítulo especialmente interesante para nuestro asunto sobre «El mito helénico y el estudio del griego» en pp. 93-108), cuyas conclusiones pretenden en parte moderar el «tono marcadamente pesimista» de la obra de Gil (p. 22; agradezco vivamente a la Dra. M. J J. Lacarra la indicación de este trabajo, así como su preciosa asistencia bibliográfica en general). Para otra visión no menos pesimista cf. p. ej. V. Lloréns, «La discontinuidad española. La invasión árabe y el legado de la antigüedad clásica», Revista de Occidente, 41, 1973, pp. 3-23. 
Bizancio) ${ }^{4}$ y ha de reconocerse que la participación de España en esta disputa - dejando al margen su determinante labor de mediación inicial — fue modesta, tardía y, sobre todo, muy subsidiaria en general de la especulación in Aristotelicis que se realizaba más allá de sus fronteras, con el París del siglo XIII como foco principalísimo. ${ }^{5}$ Según se ha sugerido a menudo, el motivo básico de esta relegación no es otro, probablemente, que la extrema y casi permanente debilidad del «aparato cultural» de la península en su aspecto puramente filológico (muy insuficiente dominio del griego ${ }^{6} \mathrm{y}$ proporcionalmente escasa producción en latín) ${ }^{7}$, como resultado comprensible de una historia harto ajetreada, rica pero también muy singular en el contexto occidental.

Las vías de acceso del aristotelismo en la España medieval son, como se sabe, bastante diversas, pero es la penetración árabe la que lo determina en buena parte. ${ }^{8}$ Sin voluntad de

4 Cf. p. ej. P. Lemerle, Le premier humanisme byzantin. Notes et remarques sur enseignement et culture à Byzance des origines au Xe siècle, París, 1971, pp. 210 y ss. y passim, H. Hunger, «Platonismus und Aristotelismus in Byzanz», Die hochsprachliche profane Literatur der Byzantiner, I: Philosophie, Rhetorik, Epistolographie, Geschichtsschreibung, Geographie, Múnich, 1978, pp. 11-41.

5 Cf. F. van Steenberghen, Aristotle in the West. The origins of Latin Aristotelianism, tr. L. Johnston, 2.. ed., Lovaina, 1970 [1954], pp. 59-88 y 89-130; A. Martínez Casado, «Aristotelismo hispano en la primera mitad del siglo XIII», Estudios filosóficos, 33, 1984, pp. 59-84 (aunque nos parezca que la existencia de un «aristotelismo activo, bien desarrollado» [p. 83] entre los clérigos leoneses en torno a 1236 precisa más prueba).

6 Sobre el griego en la península durante la antigüedad tardía y el medievo las referencias existentes son contadas: cf. M. C. Díaz y Díaz, «La cultura de la España visigótica del siglo VII», en De Isidoro al siglo XI. Ocho estudios sobre la vida literaria peninsular, Barcelona, 1976, pp. $21-55$ (espte. pp. 52-53: «El conocimiento del griego», con alusión a Pascasio, Isidoro y Julián de Toledo; su conclusión es clara: «Creo sinceramente que cuanto se afirme de conocimiento suficiente de griego por parte de nuestros autores, no puede pasar de una conjetura, con fundamento más o menos revisable»); W. Berschin, Griechisch-lateinisches Mittelalter. Von Hieronymus zu Nikolaus von Kues, Berna-Múnich, 1980; A. Bravo, «Aspectos de la cultura griega en la península ibérica durante la edad media», Euphrosyne, 17, 1989, pp. 361-372. Ya en los siglos XIII y XIV cabe mencionar a Arnaldo de Vilanova, Raimundo Lulio, Juan de Aragón, etc. (cf. A. Gómez, pp. 93 y ss.); no obstante, hablar de helenismo en España con anterioridad al siglo XVI nos parece que sigue siendo una temeridad, a pesar de las apariencias (cf. p. ej. la desilusión expresada por A. Gómez, p. 102: «Este y otros testimonios de parecida catadura, que, en un principio, me inducian a sospechar la existencia de un incipiente helenismo en Castilla a mediados del siglo XV, no han resistido ni siquiera los primeros envites de una aproximación crítica»); los encargos de Juan Fernández de Heredia (cf. A. Luttrell, «Greek histories translated and compiled for Juan Fernández de Heredia, Master of Rhodes, 1377-1396», Speculum, 35, 1960, pp. 401-407), no son apenas indicativos de un auténtico surgir de los estudios griegos (respecto al humanismo de Fernández de Heredia compartimos la opinión de J. M. Cacho, «Introducción a la obra literaria de Juan Fernández de Heredia», en I Curso sobre lengua y literatura en Aragón (Edad Media), Zaragoza, 1991, pp. 171-195, muy espte. pp. 194-195).

7 Cf. Fco. Rico, «Las letras latinas del siglo XII en Galicia, León y Castilla», Ábaco, 2, 1969, pp. 9-91; J. L. Moralejo, «Literatura hispano-latina (siglos V-XVI)», en J. M.. Díez Borque (coord.), Historia de las literaturas hispánicas no castellanas, Madrid, 1980, pp. 13-137; el nivel tampoco subió más tarde, como ha destacado L. Gil, p. 26.

8 La importancia de las traducciones de Toledo, p. ej., ha sido ya justamente sopesada a este respecto (sobre su modus operandi en general cf. M. Brasa, «Traducciones y traductores toledanos», Estudios filosóficos, 62, 1974, pp. 129137; sobre el profundo significado cultural de la presencia árabe en nuestro suelo cf. p. ej. J. Vernet, La.cultura hispanoárabe en oriente y occidente, Barcelona-Caracas-Méjico, 1978, passim). Ha de reconocerse, por otra parte, que, pese a su trascendental importancia, el Aristoteles Arabus no siempre sirve para restituir la literalidad del texto griego genuino, por su carácter a menudo peri- y parafrástico (cf. p. ej., a propósito de los Parva naturalia, A. Escobar, Die Textgeschichte der aristotelischen Schrift MEPI ENIחNISN. Ein Beitrag zur Überlieferungsgeschichte der Parva naturalia, Diss. FU, Berlín, 1990 [microf.], pp. 27-30). 
sobredimensionar esta contribución fundamental al desarrollo de la escolástica medieval, ${ }^{9}$ es necesario destacar la importancia de las obras de Avicena y Averroes, destinadas a ejercer una poderosa influencia en muchos campos, ${ }^{10}$ así como la puesta en circulación de obras como el pseudo-aristotélico Secretum secretorum (merced, p. ej., a la traducción de Juan de Sevilla), tan relevantes en el ámbito cultural del medievo español y del europeo en su conjunto. ${ }^{11}$

No obstante, ha de reconocerse igualmente que los intentos de apropiación del nuevo sistema en la península fueron a menudo pintorescos (la divertida historia del Aristoteles Hispanus nos parece un buen ejemplo) ${ }^{12}$ o meramente testimoniales, mientras que la auténtica labor de absorción del aristotelismo - via philologica - se realizaba en otros lugares y sobre bases mucho más sólidas, como son la copia efectiva de los manuscritos griegos que servirán de testigos para la tradición latina (no sólo en Constantinopla y Bizancio: también en el Sur de Italia y en otros centros de excepcional importancia en la transmisión del legado antiguo $)^{13}$ o la exégesis sistemática del pensamiento aristotélico para aprovechamiento del orbe cristiano (como la elaborada por Santo Tomás, la implícita en las primeras traducciones latinas relevantes, ${ }^{14}$ etc.)

9 Resulta muy interesante al respecto la contribución de W. Berschin, «Traduzioni in latino nel secolo XIII», en C. Leonardo - G. Orlandi (eds.), Aspetti della letteratura latina nel secolo XIII. (Atti del primo Convegno internazionale di studi dell'Associazione per il Medioevo e I'Umanesimo latini [A.M.U.L.], Perugia 3-5 ottobre 1983), Perugia - Florencia, 1986, pp. 229-242, donde se destacan las ideas de Jourdain y Minio-Paluello sobre la preeminencia del griego respecto al árabe en la transmisión occidental de Aristóteles (pp. 230-231).

10 Gracias en buena parte a los desvelos de Miguel Escoto en Toledo (cf. p. ej. W. Berschin, ib., pp. 231-235).

11 Cf. W. F. Ryan - Ch. B. Schmitt, Pseudo-Aristotle, The Secret of secrets. Sources and influences, Londres, 1982, y también, recientemente, H. O. Bizzarri, Pseudo-Aristóteles, Secreto de los secretos (Ms. BNM 9428), Buenos Aires, 1991. Sobre el Pseudo-Aristóteles y su significado en general cf. Ch. B. Schmitt - D. Knox, Pseudo-Aristoteles Latinus. A guide to Latin works falsely attributed to Aristotle before 1500, Londres, 1985; Ch. B. Schmitt, «Pseudo-Aristotle in the Latin Middle Ages», en J. Kraye - W. F. Ryan - Ch. B. Schmitt, Pseudo-Aristotle in the Middle Ages. The Theology and other texts, Londres, 1986, pp. 3-14. Quizá conviniese - dicho sea de paso- comenzar ya a distinguir terminológicamente entre el Pseudo-Aristóteles antiguo (Mech., Col., Probl., Virt., etc.) y el medieval, de origen griego más que dudoso.

12 Cf. Fco. Rico, «Aristoteles Hispanus: en torno a Gil de Zamora, Petrarca y Juan de Mena», en A. Egido (et al.), Mitos, folklore y literatura, Zaragoza, 1987, pp. $57-77$ ( =IMU, 10, 1967, 143-164, en versión ampliada con la «Posdata» de pp. 76-77).

13 Cf. p. ej., a propósito de la recensio Messanensis de la Ética a Eudemo, D. Harlfinger, «Die Überlieferungsgeschichte der Eudemischen Ethik», en Untersuchungen zur Eudemischen Ethik, Akten des 5. Symposium Aristotelicum, Berlín, 1971, pp. 1-50 (conclusiones recogidas en la reciente edición oxoniense de R. R. Walzer - J. M. Mingay, Oxford, 1991, pp. V-XII) y, en general, D. Harlfinger, Die Textgeschichte der pseudo-aristotelischen Schrift ПЕPI ATOMSN ГPAMMSN. Ein kodikologisch-kulturgeschichtlicher Beitrag zur Klärung der Überlieferungsverhältnisse im Corpus Aristotelicum, Amsterdam, 1971, pp. 60-62.

14 Como las de Guillermo de Moerbeke (tan útiles para Sto. Tomás, que -como su maestro Alberto Magno- desconocía el griego: cf. W. Berschin, art. cit., p. 241) o las de Roberto Grosseteste. Sobre el Aristoteles Latinus, aparte del célebre repertorio de G. Lacombe (et al.), Aristoteles Latinus, I-II (Roma, 1939 y Cambridge, 1955; con supl. de L. Minio-Paluello, Brujas-París, 1961), cf. B. G. Dod, «Aristoteles Latinus», y Ch. H. Lohr, «The medieval interpretation of Aristotle», en N. Kretzmann - A. Kenny - J. Pinborg - E. Stump (eds.), The Cambridge history of later medieval philosophy. From the rediscovery of Aristotle to the disintegration of scholasticism, 1100-1600, Cambridge (...), 1982, pp. 45-79 y 80-98, respectivamente. 
El rescate del auténtico Aristóteles se estaba fraguando, efectivamente, al calor de Bizancio, donde la edición de los textos del corpus comenzaba a ser extensa y daba lugar a la elaboración de comentarios, paráfrasis, etc. El nuevo aristotelismo, por supuesto, circulaba en griego y en latín, circunstancia que, sin duda, no favoreció a nuestros eruditos ${ }^{15}$ y que, como era de esperar, condicionó negativamente la recepción en España de los autores clásicos en general. Aristóteles sólo es, en este contexto, un caso de especial trascendencia; ${ }^{16}$ al respecto, es muy elocuente y significativa la relativa escasez de copias medievales del corpus aristotélico, autóctonas o no, que todavía se conservan en el fondo griego - y aun latino- de nuestras bibliotecas. ${ }^{17}$

Quizá convenga recordar que Aristóteles presentaba además para el lector medieval - como, dicho sea de paso, para el mejor pertrechado lector de hoy - una gran serie de dificultades intrínsecas, motivadas en parte por su peculiar historia textual, que ya determinó su relativamente escasa «asimilación» por los enciclopedistas romanos y epitomistas tardíos en general..$^{18} \mathrm{El}$ carácter «esotérico» de los tratados conservados también ha determinado, sin duda, que no fuera un autor de lectura fácil; de ahí la acusación de «oscuridad» que sobre ellos se cernió desde época bizantina. El hecho de tratarse de un texto complejo, plagado de contradicciones y, por consiguiente, poco propenso a la utilización dogmática 0 edificante ${ }^{19}$ bien pudo condicionar la limitación de su manejo en general. En este sentido, tampoco puede olvidarse su permanente contraposición con el representante

15 Buena muestra de ello es la relativamente escasa presencia de comentarios medievales de origen hispánico en los repertorios recopilados por $\mathrm{Ch}$. H. Lohr, «Commentaires médiévaux latins d'Aristote», en Traditio 23-30, 1967-1974, Commentateurs d'Aristote au moyen-âge latin. Bibliographie de la littérature secondaire récente, Friburgo de Brisgovia - París, 1988; cf. más recientemente la contribución al respecto de Ch. Heusch, en la reciente pero utilísima revista Atalaya: «Index des commentateurs espagnols médiévaux d'Aristote (XII'-XVe siècles)», Atalaya, 2, 1991, pp. 157-175.

16 Cf. R. R. Bolgar, The classical heritage and its beneficiaries, Cambridge - Londres - Nueva YorkMelbourne, 1977 (1954), pp. 509-511 (con las matizaciones de A. Gómez, pp. 17-18), M. ${ }^{\mathrm{a}}$ R. Lida de Malkiel, «La tradición clásica en España. A propósito de Gilbert Highet, The classical tradition. Greek and Roman influences on Western literature (...)», en La tradición clásica en España, intr. Y. Malkiel, Barcelona, 1975, pp. 339-397; a propósito de Aristóteles cf. espte. pp. 375 y 397.

17 Cf. P. Moraux - D. Harlfinger - D. Reinsch - J. Wiesner, Aristoteles Graecus. Die griechischen Manuskripte des Aristoteles, I: Alexandrien - London, Berlín - Nueva York, 1976, pp. 140-181 (Escorial); no enriquece significativamente el resul tado la consulta del Catálogo de los códices griegos de la Biblioteca Nacional de G. De Andrés (Madrid, 1987) o del célebre Rapport de Graux - Martin (París, 1892).

18 Cf. p. ej., con bibliografía, A. Escobar, «Reminiscencias aristotélicas en el De divinatione ciceroniano. Reflexiones en torno a la edición de Aristóteles en la Roma del s. I a. C.»,CFC (Est. gr. e ind.), n. s. 2, 1992, pp. 237-248.

19 Cf. p. ej. el testimonio de Petrarca recogido por Fco. Rico, El sueño del humanismo. De Petrarca a Erasmo, Madrid, 1993, p. 139; tanta flexibilidad y complejidad - mutatis mutandis- como la que se desprende p. ej. de la lectura de la Poética, desconocida en occidente hasta muy tarde pero que resultó de enorme trascendencia para el ejercicio literario del XVI (cf. p. ej. A. K. Forcione, Cervantes, Aristotle and the Persiles, Princeton, 1970); en este sentido, siempre fue mucho más dócil y asumible la preceptiva del buen Horacio. 
del otro gran paradigma, Platón, ${ }^{20}$ una polémica de fondo ideológico que tanto habría sorprendido al propio Aristóteles y que acabó provocando la aparición y desarrollo de todo un género literario.

No obstante, la dificultad formal y conceptual que planteaba el corpus se fue capeando, sin duda por el interés de su contenido desde el punto de vista filosófico-teológico, moral, científico, etc. Se trataba, en fin, de una autoridad difícil de asimilar, a menudo de dos filos, pero siempre necesaria y utilizada en última instancia, aunque sólo fuese de manera vaga e indefinida, como representante de una serie de principios escasamente delimitados pero que comenzaban a actuar decisivamente en el pensamiento medieval o pre-humanístico: racionalismo, ${ }^{21}$ naturalismo (con todo lo que la declaración del poder omnímodo de natura podía llegar a suponer) y un largo etcétera de asideros intelectuales de enorme atractivo para los talantes más rebeldes, innovadores o críticos.

El interés en España por la doctrina del philosophus philosophorum vino marcado sin duda por los condicionamientos apuntados y se manifestó en dirección similar a la que encontramos en otros países: en el campo de la especulación filosófico-teológica, en el de la ética ${ }^{22}$ - a veces de manera anacrónica y forzada,$-{ }^{23}$ en el de la teoría científica o pseudo-

20 Cf. recientemente N. G. Round, Libro llamado Fedrón. Plato's Phaedo translated by Pero Diaz de Toledo (MS Madrid, Biblioteca Nacional Vitr. 17, 4), Londres - Madrid, 1993, espte. pp. 41-61; la traducción se hizo, una vez más, sobre intermediario latino (L. Bruni; cf. ib., p. 7).

21 A menudo frente al dogma de la fe; cf. p. ej. O. H. Green, España y la tradición occidental: el espíritu castellano en la literatura desde el Cid hasta Calderón, tr. C. Sánchez, Madrid, 1969 (=Spain and the Western tradition: the Castilian mind in literature from El Cid to Calderón, Madison, 1963), III, p. 339, a propósito de Siger de Brabante.

22 La razón era apuntada por el Príncipe de Viana en el prólogo de su traducción (cf. M. Menéndez Pelayo, Biblioteca de traductores españoles, ed. E. Sánchez Reyes, Santander, 1953, IV, p. 354): «el pozo de la moral philosophía el Aristótiles fué, e los que después scribieron pozadores son»; al respecto cf. A. R. D. Pagden, «The diffusion of Aristotle's moral philosophy in Spain, ca. 1400 - ca. 1600», Traditio, 31, 1975, pp. 287 y ss.; Ch. Heusch, «Entre didactismo y heterodoxia: vicisitudes del estudio de la Ética aristotélica en la España Escolástica (siglos XIII y XIV)», La Corónica, 19, 1990-91, pp. 89-99, donde se postula, con buenas razones, que la difusión limitada de la ética aristotélica en España antes del s. XV pudo deberse al riesgo de heterodoxia que suponía y a la competencia de la literatura sapiencial, tan extendida en la península como recoge M. J. Lacarra, «La imagen de los filósofos en los textos gnómicos del siglo XIII», en J. M. Ayala (coord.), Actas del I Congreso Nacional de Filosofia Medieval, Zaragoza, 1992, pp. 45-63; la figura del Estagirita seguirá siendo autoridad todavía por mucho tiempo (cf. S. Gilman, La España de Fernando de Rojas. Panorama intelectual y social de La Celestina, Madrid, 1978 [= The Spain of Fernando de Rojas. The intellectual and social landscape of La Celestina, Princeton, 1972], pp. 138, 329 y ss.), a pesar de la erosión folklórica motivada por la leyenda del «Aristóteles cabalgado», etc. (cf. J. Storost, «Zur Aristoteles-Sage im Mittelalter. Geistesgeschichtliche, folkloristische und literarische Grundlagen zu ihrer Erforschung», en H. Nottarp (ed.), Monumentum Bambergense. Festgabe für Benedikt Kraft, Múnich, 1955, pp. 298348; J. A. Maravall, «La estimación de Sócrates y de los sabios clásicos en la Edad Media española», en Estudios de historia del pensamiento español, I: Edad Media, 3. ${ }^{\mathrm{a}} \mathrm{ed} .1983$ (2. $\left.{ }^{\mathrm{a}} \mathrm{ed} .1973\right)$, pp. 269-330 (= RABM 62, 1, 1957), espte. pp. 297-302).

23 Como en la polémica acerca de la esclavitud «natural» (cf. A. Bravo, «Los Parva naturalia en el aristotelismo español: Alonso de Freylas y sus opiniones sobre la adivinación por medio de los sueños», en Los humanistas españoles y el humanismo europeo. (IV Simposio de Filología Clásica), Murcia, 1990, pp. 51-77, en pp. 56-57), que luego sería tan encendida p. ej. entre Ginés de Sepúlveda y Bartolomé de las Casas, como recuerda O. H. Green, II, pp. 176-177. 
científica, etc. El interés por la obra aristotélica también obedecía a veces a motivos aislados y menos sistemáticos, de dudosa 0 , al menos, no exclusiva filiación aristotélica, como es el vasto tema del microcosmos, el de la psicología y la fisiología -rudimentarias pero sólidas- de los Parva naturalia, etc. Ha de reconocerse que, aunque la producción española en general nunca haya sido extraordinaria en número y calidad, el rastro del aristotelismo, más o menos explícito, no deja de percibirse en nuestra cultura de la época. Por otro lado, las circunstancias a las que - un tanto saltuariamente - hemos aludido no impidieron que la imagen de Aristóteles fuera cada vez más pujante en nuestra cultura medieval y pre-humanística. La autoridad del «Filósofo» - real o intuida - comenzó a ser indiscutible y sirvió para dar marchamo e ilustrar - patente o latentemente - muchos asertos (heterodoxos en más de un caso), como se desprende del examen de tantos pasajes literarios. ${ }^{24}$

A la limitación que supusieron el desconocimiento casi absoluto del griego (sólo en cierto modo parecida a la que se daba en los países del entorno ${ }^{25}$ ) y la impericia manifiesta de nuestro latín comenzó a añadirse muy pronto la presión de la España baluarte del cristianismo (como luego lo sería del catolicismo frente a la Reforma), poco propensa o permeable a la indagación y estudio de las fuentes. No conviene concebir esta mutilación cultural - de consecuencias en muchos terrenos, aparte del filosófico o teológico-como la única causa de nuestro «letargo» humanístico, pero tampoco se le ha de restar importancia como factor coadyuvante, capaz de neutralizar en buena parte estímulos tan importantes como fueron las corrientes de nueva espiritualidad que culminarían en la también frustrada eclosión erasmista. ${ }^{26}$

24 Cf. F. van Steenberghen, pp. 198-229, Fco. Rico, «"Por aver mantenencia". El aristotelismo heterodoxo en el Libro de buen amor», en Homenaje a José Antonio Maravall, Madrid, 1986, III, pp. 271-297 [=El Crotalón, 2, 1985, pp. 169-198], con un excelente comentario sobre el sentido aristotélico de las coplas 71-76 (para un paralelo más de la unión entre natura y pervivencia cf. p. ej. apud Gelio I 6, 2). El Aristóteles medieval, efectivamente, despertaba admiración pero también un razonable recelo en toda la cristiandad: cf. M. Grabmann, «Aristoteles im Werturteil des Mittelalters», en Mittelalterliches Geistesleben. Abhandlungen zur Geschichte der Scholastik und Mystik, II, Hildesheim-Zúrich-Nueva York, 1984 [Múnich, 1936], pp. 63-102 (p. ej. sobre la polémica del Utrum Aristoteles sit salvatus).

25 Nuestra tradición en lenguas clásicas es, no obstante, poco comparable en última instancia a la de países como Italia, Inglaterra, etc. (pese a las matizaciones de A. Gómez, pp. 99, 103, etc.); nos parece feliz al respecto la apretadísima síntesis de Fco. Rico, «El quiero y no puedo de Santillana», en Primera cuarentena y Tratado general de literatura, Barcelona, 1982, pp. 33-34, en p. 33: «[...] el drama del prehumanismo español: la tragicomedia de una élite de curiales y nobles deslumbrados por la cultura de moda en Italia, e incapaces de seguirla (o aun comprender de qué iba en realidad) por haberse criado a pechos de una tradición intelectual enteramente distinta»; en parte, creemos, por la razón apuntada (la Gramática siempre madre del progreso auténtico), sin entrar ya en las razones de carácter más ideológico y social que han dado Maravall o Gil en sus trabajos: desinterés ancestral por el conocimiento puro, conformismo con el orden establecido que propiciaban clero y nobleza, preferencia por la doctrina hecha, al margen de la cual nada se sabe o se quiere saber (santa ignorancia), identificación de ciencia y lucro, censura, nefasta política libraria desde los tiempos de Felipe II -y aun mucho antes- hasta hoy, etc.

26 A la que estarían tan vinculados «aristotélicos» como J. de Vergara y otros. 
Es evidente que las condiciones objetivas para un despegue filológico en nuestras humanidades no se produjeron hasta finales del siglo XV o principios del XVI, ${ }^{27}$ cuando el aristotelismo ya era en parte algo desfasado e Italia, que ya se había instalado en otras coordenadas filológicas y mentales ${ }^{28}$ se interesaba por un Aristóteles bien distinto: el minuciosamente «reconstruido» por el estudio de los textos griegos, gracias, en buena medida, a la ímproba labor propedéutica de los maestros huidos de Constantinopla y refugiados en la floreciente Italia del siglo XV. ${ }^{29}$

No es casual que precisamente por entonces, cuando el Aristóteles de siglos comenzaba a periclitar y a verse felizmente superado, un grupo de notables humanistas del Renacimiento español -ya con rudimentos de griego y latín suficientes, tras el ensayo de la Políglota Complutense; con vivo interés por los manuscritos, por la edición crítica de textos, etc.se proponga nada menos que llevar a cabo la edición griega del maestro (ya publicada - casi completa - en Venecia, 1495-1498).$^{30} \mathrm{Si}$ la iniciativa - muerta de entrada— no prospera, es porque - lamentablemente - no podía ser de otro modo. Pero no vamos a entrar aquí en la fortuna de Aristóteles en nuestro siglo XVI, que bien merece atención aparte.

Creemos, en suma, que la escasa pervivencia —casi podría hablarse de «supervivencia»- de Aristóteles en España estuvo determinada por una serie de factores bien conocidos y aquí sólo esbozados, entre los cuales creemos ha de seguir destacándose la secular insuficiencia técnica de nuestro humanismo filológíco. La mala fortuna del filósofo en nuestro suelo bien puede servir -ideologías aparte-para ilustrar ese peculiar décalage

27 La labor de traducción que se documenta con anterioridad («medievalizante» a menudo; al respecto cf. P. Rusell, Traducciones y traductores en la Península Ibérica (1400-1550), Bellaterra, 1985, espte. pp. 6162) apenas resulta de valor esencial; sobre A. de Cartagena y su preferencia por la traducción supuestamente realizada por Boecio cf. observaciones de interés en A. Gómez, p. 105.

28 Al respecto cf. la ya clásica contribución de S. Rizzo, Il lessico filologico degli umanisti, Roma 1984 (1973); en el fondo se produjo por entonces la eclosión de la forma mentis moderna, revolucionaria y generadora de una riqueza cultural sin igual, que todavía hoy nutre buena parte de la actividad filológica; el fenómeno lo observó con su acostumbrada lucidez E. Garin, Medioevo y Renacimiento. Estudios e investigaciones, tr. R. Pochtar, Madrid, 1983 [1981; = Medioevo e Rinascimento. Studi e ricerche, Roma-Bari, 1973], pp. 149-150 («Es el bárbaro quien busca en Aristóteles a otro sí mismo; el hombre «humano», en cambio, busca al verdadero Aristóteles y, a medida que lo va encontrando y va delineando mejor su figura, va encontrando su propia originalidad frente a él y va siendo él mismo», pp. 151-152). Aristóteles deja de confundirse con la realidad en sí para convertirse en uno más de sus intérpretes.

29 Como ha estudiado últimamente N. G. Wilson, From Byzantium to Italy: Greek studies in the Italian Renaissance, Londres, 1993; sobre nuestro pobre Demetrio Ducas cf. p. ej., con bibliografía, A. Escobar, "Notas en torno al supuesto autógrafo de Demetrio Ducas: el Ambr. C 195 inf.», en Actas del I Simposio sobre humanismo y pervivencia del mundo clásico, Alcañiz, 8-11 de mayo de 1990 (en prensa).

30 Nos referimos a la llamada «Academia aristotélica» de Trento, sobre la que sigue siendo esencial $\mathrm{Ch}$. Graux, Los orígenes del fondo griego del Escorial, tr. y notas de G. De Andrés, Madrid, 1982 [= Essai sur les origines du fonds grec de l'Escurial, París, 1880], pp. 96-102; cf. igualmente D. Harlfinger, Textgeschichte, pp. 78-85, y, sobre algunos de estos humanistas, A. Escobar, "Some Spanish autographs of the 16th century», en Fourth International Conference on Greek Palaeography (Lincoln College, Oxford, 23-29 de agosto de 1993) (inéd.) 
- si vale el eufemismo - de la cultura española respecto a la ostentada por los países del llamado «entorno europeo». ${ }^{31} \mathrm{El}$ fenómeno debe ponerse de manifiesto con rigor, sin dolor (amica patria sed...), desde la absoluta seguridad de que todavía cabe encontrar algunas flores entre los todavía poco explorados frutos de nuestro aristotelismo medieval y prehumanístico. ${ }^{32}$

31 Una de las citas más recordadas, por dolorosa, al respecto sigue siendo E. R. Curtius, «El "retraso" cultural de España», en Literatura europea y Edad Media Latina, tr. M. Frenk Alatorre - A. Alatorre, I-II, Méjico - Madrid - Buenos Aires, 1976 (= Europäische Literatur und lateinisches Mittelalter, Berna, 19542, 1948), II, pp. 753-756. Algunos creen seguir detectando lo mismo en nuestros días, como el resultado de una especie de maldición histórica o invencible sofisma (Aquiles y la tortuga, pongamos por ejemplo).

$32 \mathrm{Y}$, en este sentido, sería muy bienvenida la elaboración de un trabajo sistemático sobre los pecios de nuestra cultura grecolatina medieval, siempre tan difícilmente localizables y rescatables, basado en el estudio directo y la revisión de manuscritos y fuentes documentales, estén recogidos o no en el útil pero necesariamente incompleto repertorio del benemérito P. 0 . Kristeller, Iter Italicum. Accedunt alia itinera. A finding list of uncatalogued or incompletely catalogued humanistic manuscripts of the Renaissance in Italian and other libraries, vol.IV (alia itinera, II): Great Britain to Spain, Londres-Leiden, etc. 1989. 